\title{
Can peak expiratory flow be measured accurately during a forced vital capacity manoeuvre?
}

\author{
D. Wensley, D. Pickering, M. Silverman
}

Can peak expiratory flow be measured accurately during a forced vital capacity manoeuvre? D. Wensley, D. Pickering, M. Silverman. (C)ERS Journals Ltd 2000.

ABSTRACT: Spirometry and peak flow measurements traditionally depend on different forced expiratory manoeuvres and have usually been performed on separate, dedicated equipment. As spirometry becomes more widely used in primary care settings, the authors wished to determine whether there was a systematic difference between peak expiratory flow (PEF) derived from a short sharp exhalation (PEF manoeuvre) and from a full forced vital capacity (FVC) manoeuvre, using the same turbine spirometer (Microloop, Micro Medical, Kent, UK).

Eighty children ( 38 with current asthma) aged 7-16 yrs were asked to perform 2 blocks of PEF and FVC manoeuvres, the order being randomly assigned.

PEF obtained from a peak flow manoeuvre (PEFPF) was significantly greater than that from a forced vital capacity manoeuvre (PEFVC) in both healthy (group mean difference $20 \mathrm{~L} \cdot \mathrm{min}^{-1} ; \mathrm{p}<0.001$ ) and asthmatic children (group mean difference $\left.9 \mathrm{~L} \cdot \mathrm{min}^{-1} ; \mathbf{p}<0.004\right)$.

For clinical purposes, a mean difference of about $3 \%$ for children with asthma is of no practical significance, and peak expiratory flow data can usefully be obtained during spirometric recordings.

Eur Respir J 2000; 16: 673-676.

Home monitoring of peak expiratory flow (PEF) is advocated for asthma self-management. It allows fine tuning of asthma control by patients and has been shown in adults to improve well-being and reduce the need for hospital admission [1]. However the validity of this measurement has been questioned recently, particularly in relation to the use of the mini-Wright peak flow meter [2] and in comparison with other lung function tests [3]. A poor clinical correlation between PEF measurements and symptoms has been repeatedly shown in clinical trials and borne out in clinical experience. The most common observation is that peak flow remains within acceptable limits while patients exhibit a wide range of symptoms. In place of PEF meters, spirometry has been advocated for monitoring adults and children with asthma at home $[4,5]$.

Electronic spirometry provides much more information about airway function while still providing a value for PEF. Discrepancies have been demonstrated between PEF measured by portable PEF meters and during spirometry [6] but little work has been done to determine whether the difference is physical, related to recording equipment itself, or biological, dependent on the type of forced expiratory manoeuvre required. Nevertheless, electronic recording spirometers are increasingly being used in primary care and domiciliary settings to record PEF and spirometric indices. The authors aimed to test the hypothesis that in children, the value of PEF from a peak flow manoeuvre is equal to that obtained during a forced vital capacity manoeuvre.
Dept of Child Health, University of Leicester, Leicester, UK.

Correspondence: D.C. Wensley, Dept of Child Health, University of Leicester, Robert Kilpatrick Clinical Sciences Building, Leicester Royal Infirmary, PO Box 65, Leicester LE2 7LX, UK. Fax: 44 1162523282

Keywords: Children peak expiratory flow spirometry

Received: March 232000

Accepted after revision July 92000

This work was supported by the National Asthma Campaign.

Methods

Subjects

Children aged 7-16 yrs (median age 10.5 yrs) attending outpatient clinics in secondary or community settings were invited to participate in the study. Nonasthmatic subjects $(n=42)$ were recruited if they had no current respiratory illness and no upper respiratory symptoms within the last two weeks. This group was comprised of children with orthopaedic problems and healthy siblings of asthma clinic attenders. Asthmatic subjects $(n=38)$ had physician-diagnosed asthma and were in receipt of regular anti-inflammatory treatment, at least at Step 2 of the British Thoracic Society Guidelines [7]. Any child currently taking oral corticosteroid medication for any reason or receiving nasal therapy, and any asthmatic child with unstable or acute asthma or who had taken $\beta_{2}$-agonists in the last $4 \mathrm{~h}$ was excluded.

Verbal consent was obtained from parents and children and the manoeuvres were carried out in the clinic area while children were waiting for their appointment. Eligible children were asked after instruction, to stand and give up to five blows each of the FVC and PEF manoeuvres. Any child who, after 5 attempts was unable to produce 2 blows within $5 \%$ of maximum sum of FVC+FEV1 [8] and a total of 3 peak flow manoeuvres was excluded. Nose clips were not used. The children were all volunteers and the study was approved by the Leicestershire Research Ethics Committee. 


\section{Procedure}

Children carried out the series of PEF or FVC manoeuvres, in random order to prevent bias. PEF was performed by 44 children first and FVC by 36 children. The randomization was computer generated (SPSS 6.0. SPSS Inc., Chicago, IL, USA). After instruction, each child was asked to perform up to five blows using the first assigned set of manoeuvres with a short break between each blow. The procedure was then repeated for the second set of manoeuvres. For the peak flow manoeuvre (PEFPF), children performed at least three manoeuvres until the two best were within $5 \%$, or five blows had been recorded, whichever was sooner. For the vital capacity manoeuvre (PEFVC) children performed at least three manoeuvres until the $\mathrm{FVC}+\mathrm{FEV} 1$ was within $5 \%$ for the two best blows, or five blows had been recorded, whichever came first.

All measurements were carried out on a turbine minispirometer (Microloop, Micro Medical, Kent, UK) which met American Thoracic Society (ATS) 1994 criteria for equipment [9]. Each recording can be viewed in order to permit immediate technical assessment. The value of PEF from each blow was recorded by hand. Each FVC manoeuvre was saved electronically and printed out at the end of the session. The manoeuvre with the greatest FVC+ FEV1 sum was selected and the PEF derived from that manoeuvre was used for analysis. A maximum of $25 \mathrm{~min}$ was needed to complete the whole process.

\section{Analysis}

The mean difference between the two PEF manoeuvres and the limits of agreement were determined by an Altman Bland analysis [10]. Although it is known that age, sex, and height affect PEF the crossover study design ensured that these factors were all controlled. Data from healthy and asthmatic children were analysed separately. A sample size of 40 in each group was calculated to have $90 \%$ power at the 0.01 level to detect a $10 \%$ difference in PEF between the two manoeuvres.

\section{Results}

Eighty eligible children agreed to participate in the study. Seven children ( 4 with asthma) refused to complete all the manoeuvres following randomization and were therefore, withdrawn from the study. Data are presented for 73 children. More male children than female children were recruited into both groups and although the asthmatic group were slightly older and taller this did not reach statistical significance (table 1).

Sixty three children $(86 \%)$ provided reproducible vital capacity manoeuvres ( 2 blows within $5 \%$ of maximum FVC+FEV1 sum) [8]. Fifty four children (74\%) provided reproducible FVC manoeuvres together with at least 2 peak flow blows with less than 5\% variability. Data for these children were analysed separately from those children whose technique was non-reproducible. There were no differences in age, height, sex or asthma status between reproducible and non-reproducible groups of children.
Table 1. - Anthropometric data

\begin{tabular}{lcc}
\hline & Asthma & Healthy \\
\hline Subjects n & 34 & 39 \\
Age yr* & $11(7-15)$ & $10(7-16)$ \\
Height cm** & $150 \pm 14.8$ & $142.2 \pm 14.7$ \\
Male children*** & $25(73.5)$ & $25(64.1)$ \\
PEFPF \% pred ${ }^{+}, * *$ & $103.1 \pm 18.5$ & $108.9 \pm 18.2$ \\
\hline
\end{tabular}

*: Data presented as median (range); **: data presented as mean $\pm \mathrm{SD} ; * * *$ : data in parentheses are presented as $\mathrm{n}(\%) ;{ }^{+}$: reference values calculated from [21]. PEFPF: peak expiratory flow manoeuvre; pred: predicted.

The differences in peak flow from different manoeuvres were highly significant. The difference occurred in both asthmatic and nonasthmatic children (table 2) and in both the reproducible and non-reproducible groups. There was no order effect $(\mathrm{p}<0.50)$ and no period effect $(\mathrm{p}=0.17)$. The overall mean difference between PEFPF and PEFVC was $9.7 \mathrm{~L} \cdot \mathrm{min}^{-1}$ (fig. 1), about $5 \%$, and for the asthmatic group slightly less $(3 \%)$. However, the limits of agreement were very wide, $-57.7-+38.3 \mathrm{~L} \cdot \mathrm{min}^{-1}$, a range of 96 $\mathrm{L} \cdot \mathrm{min}^{-1}$.

\section{Discussion}

The data demonstrate that by using an electronic, turbine spirometer, the value of PEF obtained from a PEF manoeuvre (a short sharp maximal blow from total lung capacity) is significantly different from that obtained during a full forced vital capacity manoeuvre, for both asthmatic and healthy children. The overall mean difference was about $5 \%$ and for the children with asthma, 3\%. Eighty seven percent of children could carry out a reproducible full forced manoeuvre successfully, fulfilling ATS criteria [8]. Seventy four percent fulfilled the criteria set for both manoeuvres.

UWYEDD et al. [6] studied children with asthma to assess the contribution of PEF monitoring at home to asthma management. They found poor agreement between PEF from meter and PEF from spirometer and concluded that "PEF recorded by a mini-Wright meter does not necessarily reflect that recorded by spirometer". Using mechanical methods, HANKINSON et al. [11] postulated that PEF meters overestimate PEF at lower flow rates and the variable error of measurements obtained using mini-Wright meters is well recognized [12]. Accepting that the nonlinearity of portable peak flow meters increases error, if the expiratory manoeuvre is also important, the error may be exaggerated by the technique employed.

Table 2. - Mean peak flow from the best peak flow manoeuvre and the best vital capacity manoeuvre

\begin{tabular}{llll}
\hline & $\begin{array}{c}\text { Peak flow } \\
\text { manoeuvre }\end{array}$ & $\begin{array}{c}\text { Vital capacity } \\
\text { manoeuvre }\end{array}$ & Significance \\
\hline $\begin{array}{c}\text { All chidren } \\
\text { (combined) }\end{array}$ & $306.9 \pm 87.2$ & $292.0 \pm 89.0$ & $\mathrm{p}<0.001$ \\
$\begin{array}{l}\text { Asthmatic children } \\
\begin{array}{l}\text { Nonasthmatic } \\
\text { children }\end{array}\end{array}$ & $326.1 \pm 100.1$ & $317.4 \pm 103.7$ & $\mathrm{p}=0.004$ \\
\hline
\end{tabular}

Data are presented as mean \pm SD. 


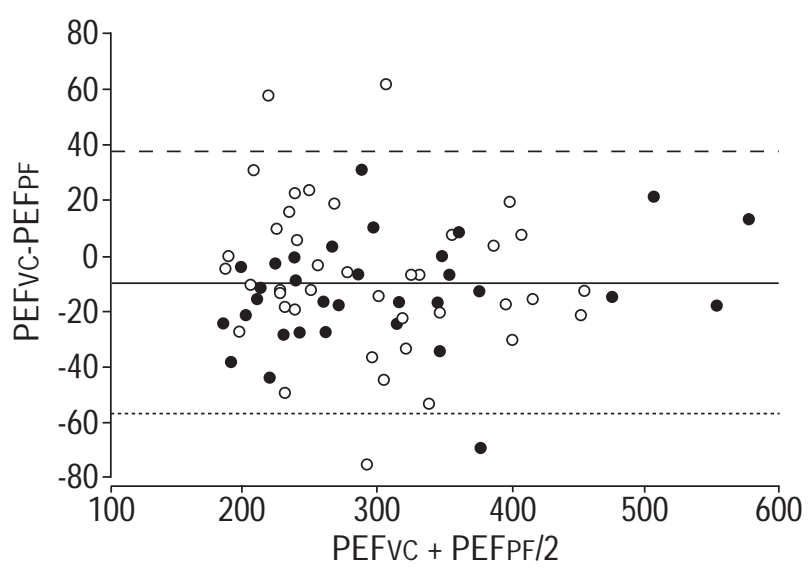

Fig. 1. - Mean difference and limits of agreement between peak expiratory flow manoeuvre (PEFPF) and vital capacity manoeuvre (PEFVC) for all subjects. *: PEFPF first; $\bigcirc$ : PEFVC first; - - - : mean $+2 \mathrm{SD} ;-$ : mean; - - - - : mean-2SD.

PEF measurement and spirometry are effort dependent manoeuvres requiring training [13]. The training effect may be quite prolonged, if increased respiratory muscle strength contributes to this [14]. Even with prior experience, young children can achieve higher flows with succeeding blows [15], so that up to 5 attempts may be insufficient to achieve the maximum PEF. This study recruited healthy children who were not used to performing lung function tests along with children with asthma, most of whom were. The children in this study were randomized to complete either the PEF or the FVC manoeuvre first so that learning did not explain the difference.

Posture might have played a part. All subjects stood to complete the manoeuvres because PEF was the result of interest [9] with no attempt to fix the head and neck posture. D'ANGELO et al. [16] suggested that changes in neck posture can impact on the FVC manoeuvre, particularly affecting the FEV1 and PEF. KANO et al. [17] also found significant changes in PEF with changing neck posture.

Guidelines should be followed in the performance of spirometry [9]. It has been suggested that there should also be standardization of the inspiratory component of the FVC manoeuvres. Inspiratory speed has been demonstrated to have an effect on PEF. A number of studies have demonstrated that with faster inspiration a larger PEF is produced $[18,19]$, although this is not necessarily true for all subjects [14]. Inspiratory speed has not been differentiated from breath-hold at total lung capacity (TLC) in most studies. A breath-hold, by reducing elastic recoil and increasing airway wall compliance, impacts on all spirometric indices, the greatest reduction being seen in the initial portion of the curve and therefore, affecting PEF and FEV1 [16, 19]. Data from WANGER et al. [18] suggest that breath-hold of as little as 2 s significantly reduces PEF, both in healthy and asthmatic adults [19]. In this study, breath-holding was not encouraged as part of the manoeuvre. No obvious pause at TLC was seen, but the length of any breath-hold was not measured. Although there are no studies assessing incidental breathhold at TLC, the authors suspect that this phenomenon is more common during a full forced manoeuvre than during a short sharp (peak flow) manoeuvre, particularly in children who may have some difficulty with instructions and coordination.

An alternative means of selection of PEF from spirometry, is simply to record the highest value from a series of blows. It was found that the mean maximum PEF selected this way, was $8 \mathrm{~L} \cdot \mathrm{min}^{-1}(2.7 \%)$ higher than the value obtained for the "best" FVC measurement, this was true for both asthmatic and healthy volunteers.

Although these results reach statistical significance, they are not clinically significant. The mean difference was $9.7 \mathrm{~L} \cdot \mathrm{min}^{-1}$. However, the limits of agreement $(-57.7-$ $\left.+38.3 \mathrm{~L} \cdot \mathrm{min}^{-1}\right)$ had a wide range of $96 \mathrm{~L} \cdot \mathrm{min}^{-1}$ which could be clinically important particularly in young children. The difference is greater than the estimated limits of agreement of PEFPF for repeated observations on a single occasion $\left(-26-+26 \mathrm{~L} \cdot \mathrm{min}^{-1}\right)$ [20]. It is not surprising that this study demonstrated wider limits than this. However, it would be important in the future to show that individual differences between the two techniques were consistent.

In summary, peak expiratory flow derived from a peak expiratory flow manoeuvre was significantly greater than that derived for a forced vital capacity manoeuvre using a turbine spirometer, for both healthy and stable asthmatic children. However, the difference was very small and of no clinical significance. Although these conclusions may not apply during acute severe episodes of airway obstruction, peak expiratory flow derived for spirometric measurements appears to be adequate for clinical monitoring.

\section{References}

1. Lahdensuo A, Haahtela T, Herrala J, et al. Randomised comparison of guided self management and traditional treatment of asthma over one year. BMJ 1996; 312: 748752.

2. Sly PD, Cahill P, Willet K, Burton P. Accuracy of mini peak flow meters in indicating changes in lung function in children with asthma. BMJ 1994; 308: 572-574.

3. Klein RB, Fritz GK, Yeung A, McQuaid EL, Mansell A. Spirometric patterns in childhood asthma: peak flow compared with other indices. Pediatr Pulmonol 1995; 20: 372-379.

4. Reddel HK, Ware SI, Salome CM, Jenkins CR, Woolcock AJ. Pitfalls in processing home electronic spirometric data in asthma. Eur Respir J 1998; 12: 853-858.

5. Pelkonen AS, Nikander K, Turpeinen M. Reproducibility of home spirometry in children with newly diagnosed asthma. Pediatr Pulmonol 2000; 29: 34-38.

6. Uwyyed K, Springer C, Avital A, Bar-Yishay E, Godfrey $\mathrm{S}$. Home recording of PEF in young asthmatics: does it contribute to management? Eur Respir J 1996; 9: 872879.

7. Anonymous. The British guidelines on asthma management. 1995 review and position statement. Thorax 1997; 52: $\mathrm{S} 1-\mathrm{S} 21$.

8. Anonymous. Standardization of Spirometry, 1987 update. Am Rev Respir Dis 1987; 136: 1285-1298.

9. Anonymous. Standardization of Spirometry, 1994 Update. American Thoracic Society. Am J Respir Crit Care Med 1995; 152: 1107-1136.

10. Bland JM, Altman DG. Statistical methods for assessing agreement between two methods of clinical measurement. Lancet 1986; 1 (8476): 307-310. 
11. Hankinson JL, Filios MS, Kinsley KB, Petsonk EL. Comparing MiniWright and spirometer measurements of peak expiratory flow. Ann N Y Acad Sci 1995; 108: 407410.

12. Miller MR, Dickinson SA, Hitchings DJ. The accuracy of portable peak flow meters. Thorax 1992; 47: 904-909.

13. Studnicka M, Frischer T, Neumann M. Determinants of reproducibility of lung function tests in children aged 7 to 10 years. Pediatr Pulmonol 1998; 25: 238-243.

14. Tzelepis GE, Zakynthinos S, Vassilakopoulos T, Geroulanos S, Roussos C. Inspiratory maneuver effects on peak expiratory flow-role of elastic recoil and expiratory pressure. Am J Respir Crit Care Med 1997; 156: 1399-1404.

15. Greenough A, Everett L, Price JF. Are we recording peak flows properly in young children? Eur Respir J 1990; 3: 1193-1196.

16. D'Angelo E, Prandi E, Milic-Emili J. Dependence of maximal flow volume curves on time course of preceding inspiration. J Appl Physiol 1991; 70: 2602-2610.

17. Kano S, Burton DL, Lanteri CJ, Sly PD. Determination of peak expiratory flow. Eur Respir J 1993; 6: 1347-1352.

18. Wanger JS, Ikle DN, Cherniack RM. The effect of inspiratory maneuvers on expiratory flow rates in health and asthma: influence of lung elastic recoil. Am J Respir Crit Care Med 1996; 15: 1302-1308.

19. Matsumoto I, Walker S, Sly PD. The influence of breathhold on peak expiratory flow in normal and asthmatic children. Eur Respir J 1996; 9: 1363-1367.

20. Strachan DP. Repeatability of ventilatory function measurements in a population survey of 7 year old children. Thorax 1989; 44: 474-479.

21. Rosenthal M, Bain SH, Cramer D, et al. Lung function in white children aged 4 to 19 years: I. Spirometry. Thorax 1993; 48: 794-802. 